\title{
Does intravenous rtPA benefit patients in the absence of CT angiographically visible intracranial occlusion?
}

P. N. Sylaja ${ }^{1,4}$, Imanuel Dzialowski ${ }^{1,3}$, Volker Puetz ${ }^{1,3}$, Michael Eliasziw $^{2}$, Michael D. Hill ${ }^{1}$, Andrea Krol $^{1}$, Christine O’Reilly ${ }^{1}$, Andrew M. Demchuk ${ }^{1}$

Departments of Clinical Neurosciences, ${ }^{1}$ Calgary Stroke Program, ${ }^{2}$ Community Health Sciences, University of Calgary, Calgary, Alberta, ${ }^{3}$ University of Dresden, Germany, ${ }^{4}$ Ananthapuri Hospitals and Research Institute, Kerala, India

Address for correspondence:

Dr. P. N. Sylaja,

Department of Neurology

Ananthapuri Hospitals and Research

Institute, Trivandrum, India.

E-mail: sylajapn@hotmail.com

DOI: $10.4103 / 0028-3886.59469$

\begin{abstract}
Background: In patients with acute stroke receiving intravenous tissue plasminogen activator (tPA), we postulated that the presence of intracranial occlusion on CT angiography (CTA) modifies the benefit of thrombolysis. Materials and Methods: Using a retrospective cohort design, we identified patients with acute ischemic stroke in our CTA database between May 2002 and August 2007. All the patients had a CTA within $12 \mathrm{~h}$ of onset, a premorbid modified Rankin scale $(\mathrm{mRS}) \leq \mathrm{l}$, and a baseline National Institute of Health Stroke Scale score(NIHSS)f $\geq 6$. The primary outcome was early effectiveness of tPA defined as an NIHSS score of $\leq 2$ at $24 \mathrm{~h}$ or a 4-point NIHSS improvement at $24 \mathrm{~h}$. Secondary outcome included $\mathrm{mRS} \leq \mathrm{l}$ at 90 days. The relationship between intracranial occlusion on CTA and benefit of tPA was assessed using a test for interaction. Results: A total of 287 patients met the criteria [occlusion present $\mathrm{N}=168$; (98 with tPA; 70 without tPA) and occlusion absent $\mathrm{N}=119$; (52 with tPA; 67 without tPA)]. Those with intracranial occlusion were likely to have more severe strokes (NIHSS $\geq 15 ; P<0.001$ ) and abnormal brain imaging (ASPECTS $\leq 7 ; P<0.001$ ). For outcome of 4 -point NIHSS score improvement at $24 \mathrm{~h}$, benefit from tPA was observed only among patients with a visible occlusion (absolute difference in favor of tPA: $20.4 \%$ vs. $0.7 \% ; P=0.06$ ). Conclusion: In patients with acute ischemic stroke, thrombolysis produced a better early clinical response among patients with intracranial occlusion, which needs to be confirmed in stroke thrombolysis trials.
\end{abstract}

Key words: Computed tomography angiography, intracranial occlusion, thrombolysis

\section{Introduction}

Intravenous thrombolysis is thought to be effective for all subtypes of acute ischemic stroke, including subcortical strokes based upon the NINDS tPA Stroke trial. ${ }^{[1]}$ However subtyping of the stroke in this trial had limitations as advanced imaging was not available at that time. Thrombolysis has significant benefit when early recanalization is achieved in patients with intracranial occlusion. ${ }^{[2,3]}$ Controversy exists regarding whether similar benefits are observed with lacunar or nonocclusive stroke. It is yet unclear whether thrombolysis should be given to patients without a large vessel occlusion. Angiographic studies have shown that a large proportion (19-39\%) of patients with acute ischemic stroke have no vessel occlusion. ${ }^{[4-7]}$ This probably occurs because of spontaneous autolysis of thrombus and a non-visible occlusion among lacunar strokes. A recent study of patients treated with tPA showed better outcome in those without intracranial occlusion, as assessed by CT angiography (CTA), but a control group was not available. ${ }^{[7]}$ It 
remains unclear if thrombolysis will benefit patients without a large vessel occlusion.

CTA is widely available and provides a rapid and accurate means of assessing intracranial vascular occlusion in an acute setting. ${ }^{[8-11]}$ The aim of the present study was to determine whether the presence of intracranial occlusion, identified from CTA, modified the response to thrombolysis in patients with acute ischemic stroke.

\section{Materials and Methods}

Patients presenting to the emergency room with acute ischemic stroke between May 2002 and August 2007 were identified from the CTA database at Foothills Hospital, Calgary, Alberta. Patients were included in the present study if they had an acute ischemic stroke and had a CTA performed within $12 \mathrm{~h}$ of symptom onset. In addition, they were required to have had a premorbid modified Rankin scale (mRS) score $\leq 1$ and a baseline National Institute of Health Stroke Scale (NIHSS) score $\geq 6$. In our centre, unless contraindicated all patients with acute stroke routinely undergo CT angiography before thrombolysis. We usually get a CT head followed immediately by a CT angiography which takes only an additional 5-10 min. All patients who came within $3 \mathrm{~h}$ of symptom onset were treated with $\mathrm{tPA}$ regardless of the findings on CT angiography, according to the current guidelines. Patients who received tPA prior to their CTA and patients who received any intraarterial device-based interventions were excluded. Neurological and functional outcomes were recorded prospectively at $24 \mathrm{~h}$ and at 90 days in the stroke clinic. The study was approved by the Institutional Review Board.

The non-contrast CT (NCCT) scan was performed on a multislice scanner (GE Medical Systems or Siemens) using $120 \mathrm{kV}, 170 \mathrm{mAs}$ with 5-mm slice thickness. CTA acquisitions were obtained after a single bolus injection of $90-120 \mathrm{ml}$ of iodinated non-ionic contrast into the anticubital vein at 3-4 ml/sec with a $20-25 \mathrm{sec}$ delay to start imaging. The imaging was autotriggered by the appearance of the contrast agent on the ascending aorta. The image sequence covered the foramen magnum to centrum semiovale with $0.6-\mathrm{mm}$ to $1-\mathrm{mm}$ slice thickness. Source images were reconstructed at $1.25,2.5$, and 4-mm slice thickness in coronal, axial, and sagittal planes. Intracranial vessel status was assessed routinely by a neuroradiologist using source images and three-dimensional (3-D) reformats for any occlusion. The Alberta Stroke Program Early CT Score (ASPECTS) was determined by a threereader consensus (one stroke neurologist and two stroke fellows) from the baseline NCCT scan. We independently rated the occurrence of hemorrhagic transformation on the 12-36 h follow-up NCCT and was classified as parenchymal hematoma $(\mathrm{PH})$ or hemorrhagic infarction (HI).

\section{Statistical analysis}

The primary outcome was a measure of the early effectiveness of tPA, defined as an NIHSS score $\leq 2$ at $24 \mathrm{~h}$, which has been shown to be the most powerful binary measure of early tPA effectiveness in the NINDS tPA Stroke trial. ${ }^{[12]}$ Another binary outcome, used to complement the primary outcome, was an improvement of $\geq 4$ points from the baseline NIHSS to the 24 -h NIHSS score. This outcome was used to assess tPA effectiveness in Part I of the NINDS trial. ${ }^{[1,13]}$ The secondary outcome was a measure of the long-term efficacy of tPA defined as an $\mathrm{mRS}$ score $\leq 1$ at 90 days. The presence (or absence) of intracranial occlusion was used as a stratification factor in the analyses. The effectiveness of tPA within stratum was tested for statistical significance using a Chi-square test. Binomial regression with a log link was used to test for interaction with regards to the effectiveness of tPA in the presence and absence of intracranial occlusion, after adjusting for potential demographic and clinical confounders. We considered an $\alpha=0.10$ for the assessment of the interaction terms as a threshold for determining significance. ${ }^{[14]}$ All other comparisons were made using $\alpha=0.05$.

\section{Results}

A total of 287 patients met the eligibility criteria. One hundred and sixty-eight had CT-angiographic evidence of intracranial occlusion (98 received tPA and 70 no rtPA) and 119 did not have intracranial occlusion (52 received tPA and 67 no rtPA). Patients with an intracranial occlusion were significantly more likely to have a more severe stroke (NIHSS $\geq 15$ ) and more likely to have significant extent of early ischemic changes on NCCT scan (ASPECTS 57) [Table 1]. Except for these two factors, the frequencies of all other characteristics were similar across both stratum and treatment arms [Table 1]. None of the demographic and clinical characteristics were identified as confounders from the regression analyses. Unadjusted results are, therefore, reported in Table 2.

In the assessment of the early effectiveness of tPA, early response from tPA was observed only among patients who had a visible intracranial occlusion on baseline CTA [Table 2]. The absolute increase in responders was $10.4 \%$ for NIHSS $\leq 2$ at $24 \mathrm{~h}$ and $20.4 \%$ for 4-point or greater improvement in NIHSS at $24 \mathrm{~h}$ compared to no rtPA group. Among patients without an intracranial occlusion visible on baseline CTA, the responder rates for NIHSS $<2$ at $24 \mathrm{~h}$ and 4 -point or 
greater improvement in NIHSS at $24 \mathrm{~h}$ were similar for those who received and did not receive $\mathrm{tPA}(-0.1,0.7 \%)$. This did not translate to 90-day outcomes as the visible occlusion group had a non-significant absolute increase in responders of $2.8 \%$ for NIHSS $\leq 2$ at three months and $1.9 \%$ for 4 -point or more improvement in NIHSS at three months compared to baseline. Among patients without a visible occlusion, the responder rates were similar to the occlusion group with NIHSS $<2$ at three months and 4-point or greater improvement of NIHSS at three months compared to baseline of $-1.8 \%$ with rtPA treatment and $-0.4 \%$ without rtPA treatment. No differences in responder rates with and without occlusion in setting of tPA treatment were seen with $\mathrm{mRS}<2$ at three months [Table 2]. As expected, the rate of parenchymal hematoma was higher among patients who received rtPA [Table 3]. The presence of visible occlusion did not significantly alter the occurrence of hemorrhage.

\section{Discussion}

The present study demonstrates that patients with intracranial occlusion on CTA are more likely to have early clinical response if rtPA is administered. This does not appear to be the case in the absence of $\mathrm{CT}$ angiographically visible intracranial occlusion. This early benefit of rtPA in the presence of intracranial occlusion did not however carry forward to differences in 90-day outcome.

Previous studies have suggested an excellent risk benefit ratio for rtPA treatment in the absence of visible intracranial occlusion. Higher rates of early improvement and lower rates of intracranial hemorrhage were seen in patients with a patent vasculature treated with rtPA. ${ }^{[5]}$ The difficulty with these studies is the lack of a comparison group of

Table 1: Demographic, clinical, and radiologic characteristics of patients

\begin{tabular}{|c|c|c|c|c|c|}
\hline \multirow[t]{2}{*}{ Characteristic } & \multicolumn{2}{|c|}{ Occlusion $=$ No } & \multicolumn{2}{|c|}{ Occlusion $=$ Yes } & \multirow[t]{2}{*}{$P$ value } \\
\hline & rtPA $=$ No $(N=67)$ & $\operatorname{rtPA}=$ Yes $(\mathrm{N}=52)$ & $\operatorname{rtPA}=\mathbf{N o}(\mathbf{N}=70)$ & rtPA = Yes (N = 98) & \\
\hline Age $>75$ years* & 47.8 & 42.3 & 38.6 & 43.9 & 0.75 \\
\hline Male sex & 58.2 & 57.7 & 60.0 & 59.2 & 0.99 \\
\hline Lacunar stroke & 17.9 & 17.3 & 0.0 & 0.0 & $<0.001$ \\
\hline Baseline NIHSS score $15-35^{+}$ & 13.4 & 26.9 & 41.4 & 53.1 & $<0.001$ \\
\hline Median baseline NIHSS score & 7 & 11 & 12.5 & 15 & $<0.001$ \\
\hline History of hypertension & 68.7 & 53.9 & 57.1 & 56.1 & 0.31 \\
\hline History of ischemic heart disease & 22.4 & 21.2 & 25.7 & 22.5 & 0.94 \\
\hline History of diabetes & 16.4 & 9.6 & 20.0 & 13.3 & 0.41 \\
\hline Baseline ASPECTS score $0-7^{+}$ & 11.9 & 17.3 & 52.9 & 41.8 & $<0.001$ \\
\hline
\end{tabular}

${ }^{*}$ Mean (standard deviation) age: 70.1 (14.6), 67.7 (18.2), 67.9 (14.1), and 68.1 (15.3) years, respectively; ${ }^{\dagger}$ Mantel-Haenszel Chi-square test for linear trend of proportions, $P$ value $<0.001$. All numbers are in percentages

\begin{tabular}{|c|c|c|c|c|c|c|c|}
\hline \multirow[t]{2}{*}{ Responder definition } & \multicolumn{3}{|c|}{ Occlusion $=$ No } & \multicolumn{3}{|c|}{ Occlusion $=$ Yes } & \multirow{2}{*}{$\begin{array}{c}\text { Interaction } \\
P \text { value }\end{array}$} \\
\hline & $\begin{array}{c}\text { rtPA = No } \\
(N=67)\end{array}$ & $\begin{array}{c}\text { rtPA }=\text { Yes } \\
(N=52)\end{array}$ & $\begin{array}{c}\text { Difference } \\
\text { P value* }\end{array}$ & $\begin{array}{c}\text { rtPA = No } \\
(N=70)\end{array}$ & $\begin{array}{c}\text { rtPA }=\text { Yes } \\
(N=98)\end{array}$ & $\begin{array}{c}\text { Difference } \\
\boldsymbol{P} \text { value* }\end{array}$ & \\
\hline NIHSS 0 to 2 at $24 \mathrm{~h}$ & 32.8 & 32.7 & $\begin{array}{l}-0.1 \\
0.99\end{array}$ & 10.0 & 20.4 & $\begin{array}{l}10.4 \\
0.08\end{array}$ & 0.14 \\
\hline NIHSS improve $\geq 4$ at 24 & 49.3 & 50.0 & $\begin{array}{c}0.7 \\
0.94\end{array}$ & 28.6 & 49.0 & $\begin{array}{c}20.4 \\
0.012\end{array}$ & 0.06 \\
\hline MRS $0-1$ at 90 days & 38.8 & 44.2 & $\begin{array}{c}5.4 \\
0.55\end{array}$ & 25.7 & 28.6 & $\begin{array}{c}2.9 \\
0.68\end{array}$ & 0.94 \\
\hline
\end{tabular}

\begin{tabular}{|c|c|c|c|c|c|c|c|}
\hline \multirow[t]{2}{*}{ Hemorrhage definition } & \multicolumn{3}{|c|}{ Occlusion $=$ No } & \multicolumn{3}{|c|}{ Occlusion $=$ Yes } & \multirow{2}{*}{$\begin{array}{c}\text { Interaction } \\
P \text { value }\end{array}$} \\
\hline & $\begin{array}{c}\text { rtPA = No } \\
(N=67)\end{array}$ & $\begin{array}{c}\text { rtPA }=\text { Yes } \\
(\mathrm{N}=52)\end{array}$ & $\begin{array}{c}\text { Difference } \\
P \text { value* }\end{array}$ & $\begin{array}{c}\text { rtPA = No } \\
(N=70)\end{array}$ & $\begin{array}{c}\text { rtPA = Yes } \\
(\mathrm{N}=98)\end{array}$ & $\begin{array}{c}\text { Difference } \\
P \text { value* }\end{array}$ & \\
\hline Any intracerebral & 6.0 & 21.2 & $\begin{array}{l}15.2 \\
0.01\end{array}$ & 24.3 & 32.7 & $\begin{array}{c}8.4 \\
0.24\end{array}$ & 0.14 \\
\hline Hemorrhagic infarction & 6.0 & 9.6 & $\begin{array}{c}3.6 \\
0.46\end{array}$ & 20.0 & 21.4 & $\begin{array}{c}1.4 \\
0.82\end{array}$ & 0.59 \\
\hline Parenchymal hematoma & 0.0 & 11.5 & $\begin{array}{l}11.5 \\
0.006\end{array}$ & 4.3 & 11.2 & $\begin{array}{l}6.9 \\
0.11\end{array}$ & 0.12 \\
\hline
\end{tabular}

$P$ value comparing percentage of hemorrhages among patients who received and did not receive rtPA 
patients who did not receive rtPA. It is intuitive that stroke patients without visible intracranial occlusion have better outcomes due to smaller regions of brain ischemia. Verro et al., confirmed this by demonstrating a high rate of good outcome (83\%) in conservatively managed patients without intracranial occlusion. ${ }^{[15]}$ But a recent study has also shown a less than $50 \%$ excellent outcome after tPA at three months in the absence of a visible intracranial occlusion and the rate of symptomatic hemorrhage after tPA 'is similar in these patients. ${ }^{[16]}$ Supporting the rationale for targeting patients with rtPA if there is intracranial occlusion is the recently completed DIAS 2 trial evaluating desmoteplase in ischemic stroke patients. ${ }^{[17]}$ This trial demonstrated a robust treatment effect of this thrombolytic agent if intracranial occlusion was visible on MRI or CTA. This has resulted in a planned trial (DIAS-3) which will randomize patients to thrombolysis with desmoteplase only if intracranial occlusion is visible.

Thrombolysis works by achieving early recanalization. The absence of occlusion target for recanalization would suggest a muted clinical effect at best. A variety of explanations have been postulated for the benefit of tPA without visible occlusion. Lacunar infarction which represents $20 \%$ of all ischemic stroke may benefit from tPA by recanalization of a small arteriolar occlusion not visible on CTA. ${ }^{[18]}$ Distal occlusions which are difficult to accurately identify by CTA could also be a target for tPA-induced recanalization. These populations might be better identified by CT perfusion techniques which are exquisitely sensitive to detecting cerebral blood flow disturbances even in small volumes. ${ }^{[7]}$

This study has limitations since it is not a randomized controlled trial. The control population who did not receive tPA had contraindication and hence is not an ideal comparison group. Any baseline differences were adjusted for in the analysis to account for this. CTA is not $100 \%$ sensitive and specific for angiographically confirmed intracranial occlusion and may have missed distal middle cerebral artery (MCA) occlusions or small perforator occlusions. CT angiographic techniques continue to evolve with new CT scanner techniques which now can combine CTA and CT perfusion with a single bolus of contrast. The choice of early clinical response measures to evaluate tPA response is based on work by Broderick et al. The early effectiveness of tPA in the NINDS rtPA Stroke Study was best identified with NIHSS score of $\leq 2$ at 24 h. $^{[12]}$ Also chosen for this study was the 4-point or greater improvement in NIHSS which was the primary outcome in the NINDS Part I study. In addition since we have included only patients with a NIHSS score of $>5$, the results are applicable only to those with moderate and severe strokes.
This data is hypothesis-generating but should not yet influence current rtPA decision-making. We feel further study of the role of rtPA in the absence of intracranial occlusion is warranted. Ongoing randomized trials of thrombolysis such as the International Stroke Trial-3 and DIAS-3 can answer the question of the value of rtPA in the non-occlusive setting if baseline $\mathrm{CT}$ angiographic data is obtained.

\section{References}

1. The National Institute of Neurological Disorders and Stroke rt-PA stroke study group. Tissue plasminogen activator for acute ischemic stroke. N Engl J Med 1995;333:1581-7.

2. Rha JH, Saver JL. The impact of recanalization on ischemic stroke outcome: A meta analysis. Stroke 2007;38:967-73.

3. Molina CA, Alexandrov AV, Demchuk AM, Saqqur M, Uchino K, Alvarez-Sabin J. Improving the predictive accuracy of recanalization on stroke outcome in patients treated with tissue plasminogen activator. Stroke 2004;35:151-7.

4. Lewandowski CA, Frankel M, Tomsick TA, Broderick J, Frey J, Clark W, et al. Combined intravenous and intra arterial r-tPA versus intraarterial therapy for acute ischemic stroke. Stroke 1999;30:2598-605.

5. Wolpert S, Bruckmann H, Green lee R, Wechsler L, Pessin M, del Zoppo G. Neuroradiologic evaluation of patients with acute stroke treated with recombinant tissue plasminogen activator. AJNR Am J Neuroradiol 1993;14:3-13.

6. del Zoppo GJ, Higashida RT, Furlan AJ, Pessin MS, Rowley HA, Gent M. PROACT: A phase II randomized trial of recombinant prourokinase by direct arterial delivery in acute middle cerebral artery stroke. Stroke 1998;29:4-11.

7. Sims JR, Rordorf G, Smith EE, Koroshetz WJ, Lev MH, Buonanno F, et al. Arterial occlusion revealed by CT angiography predicts NIH Stroke score and acute outcomes after IV tPA treatment. AJNR Am J Neuroradiol 2005;26:246-51.

8. Knauth M, von Kummer R, Jansen O, Hahnel S, Dorfler A, Sartor K. Potential of CT angiography in acute ischemic stroke. AJNR Am J Neuroradiol 1997;18:1001-10.

9. Lev MH, Farkas J, Rodriguez VR, Schwamm LH, Hunter GJ, Putman CM, et al. CT angiography in the rapid triage of patients with hyperacute stroke to intra-arterial thrombolysis: Accuracy in the detection of large vessel thrombus. J Comput Assist Tomogr 2001;25:520-8.

10. Shrier DA, Tanaka H, Numaguchi Y, Konno S, Patel U, Shibata D. CT angiography in the evaluation of acute stroke. A.JNR Am J Neuroradiol 1997;18:1011-20.

11. Wildermuth S, Knauth M, Brandt T, Winter R, Sartor K, Hacke W. Role of CT angiography in patient selection for thrombolytic therapy in acute hemispheric stroke. Stroke 1998;29:935-8.

12. Broderick JP, Lu M, Kothari R, Levine SR, Lyden PD, Haley EC, et al. Finding the most powerful measures of the effectiveness of tissue plasminogen activator in the NINDS tPA stroke trial. Stroke 2000;31:2335-41.

13. Haley HC, Lewandowski C, Tilley BC; NINDS rt-PA Stroke Study Group. Myths regarding the NINDS rt-PA Stroke trial: Setting the record straight. Ann Emerg Med 1997;30:676-82.

14. Generalized efficacy of $t$-PA for acute stroke: Subgroup analysis of the NINDS $t$-PA Stroke Trial. Stroke 1997;28:2119-25.

15. Verro P, Tanenbaum LN, Borden N, Eshkar N, Sen S. Clinical application of CT angiography in acute ischemic stroke. Clin Neurol Neurosurg 2007;109:138-45.

16. Mikulik R, Goldemund D, Reif M, Aulicky P, Krupa P. Outcome of patients with negative CT angiography results for arterial occlusion treated with intravenous thrombolysis. Stroke 2009;40:868-72.

17. Hacke W, Albers G, Al-Rawi Y, Bogousslavsky J, Davalos A, Eliasziw M, et al. The Desmoteplase in acute ischemic stroke 
trial (DIAS): A phase II MRI- based 9-hour window acute stroke thrombolysis trial with intravenous desmoteplase. Stroke 2005;36:66-73.

18. Adams HP, del Zoppo G, Alberts MJ, Bhatt DL, Brass L, Furlan A, et al. Guidelines for the early management of adults with ischemic stroke: A guideline from the American Heart Association/American Stroke Association Stroke Council, Clinical Cardiology Council, Cardiovascular Radiology and Intervention Council, and the Atherosclerotic Peripheral
Vascular Disease and Quality of Care Outcomes in Research Interdisciplinary Working Groups: The American Academy of Neurology affirms the value of this guideline as an educational tool for neurologists. Stroke 2007;38:1655-711.z

Accepted on 10-09-2009

Source of Support: Nil, Conflict of Interest: None declared.

Staying in touch with the journal

1) Table of Contents (TOC) email alert Receive an email alert containing the TOC when a new complete issue of the journal is made available online. To register for TOC alerts go to www.neurologyindia.com/signup.asp.

\section{2) RSS feeds}

Really Simple Syndication (RSS) helps you to get alerts on new publication right on your desktop without going to the journal's website. You need a software (e.g. RSSReader, Feed Demon, FeedReader, My Yahoo!, NewsGator and NewzCrawler) to get advantage of this tool. RSS feeds can also be read through FireFox or Microsoft Outlook 2007. Once any of these small (and mostly free) software is installed, add www.neurologyindia.com/rssfeed.asp as one of the feeds. 